
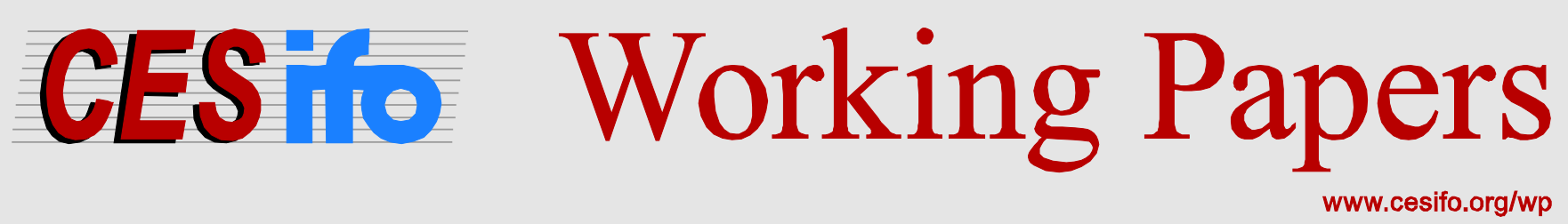

\title{
Taxation and Parental Time Allocation under Different Assumptions on Altruism
}

\author{
Alessandra Casarico \\ Alessandro Sommacal
}

CESIFO WORKING PAPER NO. 4690

CATEgORY 1: Public FinANCE

MARCH 2014
An electronic version of the paper may be downloaded
- from the SSRN website:
- from the RePEc website:
- from the CESifo website:
WwW.SSRN.com
www.RePEc.org
www.CESifo-group.org/wp

\section{CESifo}




\title{
Taxation and Parental Time Allocation under Different Assumptions on Altruism
}

\begin{abstract}
In this paper we develop an overlapping generations model in which child care matters for human capital accumulation. We investigate whether an increase in labor supply brought about by a reduction in taxes is always associated with a reduction in parental time devoted to children, which modifies their human capital accumulation process. We show that the result critically depends on the assumptions on the altruistic motives behind the choice of devoting time to children.
\end{abstract}

JEL-Code: J130, J220, J240.

Keywords: early childhood environment, child care, labor supply, warm glow, full altruism.

\author{
Alessandra Casarico \\ Bocconi University \\ Italy-20136 Milan \\ alessandra.casarico@unibocconi.it
}

\author{
Alessandro Sommacal \\ University of Verona \\ Italy-37129 Verona \\ alessandro.sommacal@univr.it
}

February 18, 2014

The paper was presented at the PET 2013 conference in Lisbon, at the IIPF 2013 conference in Taormina and at the SIEP 2013 meeting in Pavia. We thank participants for their comments. Alessandra Casarico acknowledges financial support from MIUR within a PRIN project. Alessandro Sommacal acknowledges financial support from MIUR within a FIRB project. 


\section{Introduction}

This paper examines the effects of labor income taxation on parental time allocation in an overlapping generations (OLG) model in which child care (i.e. parental time and day care services) matters for human capital accumulation. In their choice to devote time to children, parents can be motivated by warm glow or by full altruism.

There is a large policy debate on how to increase employment and the number of hours worked. In some countries this issue is particularly critical if one focuses on female labor force participation. Changes to tax policy are often considered an effective tool to increase labor supply (see Prescott 2004, Ohanian et al. 2008, Berger and Heylen 2011). At the same time, there are concerns on the impact that a higher labor force participation may have on the time allocated to children. Recent research analyses the relationship between parental time and the accumulation of human capital. For example, Del Boca et al. (forthcoming) stress that parental time is more important for the cognitive development of children than money expenditure. Bernal and Keane $(2010,2011)$ find that, on average, the substitution of maternal time with other sources of care produces negative and rather sizable effects on children's skills, especially in contexts where high quality day care institutions are absent. ${ }^{1}$ The Europe 2020 strategy has forcefully highlighted the importance of the availability of quality day care services not just as a tool which is a complement to parental labor, but as a mean to develop future cohorts' human capital and to promote equality of opportunities.

In this paper we investigate whether an increase in labor supply brought about by a reduction in taxes is always associated with a reduction in parental time devoted to children, as it is implicitly assumed in the literature. ${ }^{2}$

We develop a three-period OLG endogenous growth model. Agents are altruistic and live for three periods: childhood, parenthood and retirement. In the first period, the child only receives care. In the second period, she has one child and she determines how much to consume and save and how much time to devote to labor, leisure and her child. The child requires a certain care time; that is, the time not supplied by the parent is covered by non-parental time, e.g. day care services which the parent buys on the market. Thus, an increase of one unit of parental time is always matched by a reduction of one unit of non-parental time. Child care arrangements, that is the combination of parental and non-parental time, influence the human capital accumulation process. In the third period, the agent retires and consumes part of her income. We consider two set-ups: in the first one, altruism is of the warm glow type and the parent cares directly about the level of human capital of the child. In the

\footnotetext{
${ }^{1}$ Baker et al. (2008) draw similar conclusions. See also Bernal (2008). Havnes and Mogstad (2010) show that the focus on the mean impact of day care services on child development can also mask important differences along the earnings distribution. The effects are positive and sizable below the median of the earnings distribution.

${ }^{2}$ Notice that our focus is on purely distortionary taxation. Prior research has examined public subsidies to day care (e.g. Domeij and Klein (2013) and Blomquist et al. (2010)) but has not accounted for the role of child care on human capital accumulation.
} 
second one, the parent is fully altruistic and her utility depends on the utility of the child.

We show that the relationship between taxation and parental time critically depends on the assumption on parental altruism. If parents care about their children out of warm glow, we demonstrate that, lowering the tax rate, parental time devoted to children goes down. This happens because the opportunity cost of parental time provided to children increases when taxation declines. If parental time has a positive impact on the quality of the early childhood environment, an increase in labor supply brought about by a reduction in taxation comes at the cost of a lower human capital accumulation.

If parents care about the utility of their children because they are fully altruistic, we show that lowering taxation has an ambiguous impact on parental time and we identify a threshold level of the elasticity of labor supply at which the sign of the effect of taxation on parental time changes. In contrast to the case in which parents are warm-glow altruistic, in the presence of full altruism it may happen that a reduction in taxes increases both labor supply and parental time devoted to children. This negative relationship between taxation and parental time can be explained as follows: when taxation goes down, the returns to parental investment in children's human capital are higher because children will work more. The more elastic the response of labor supply is to changes in taxation, the more likely it is that the higher returns offset the increase in the opportunity cost of parental time. If parental time has a positive impact on the quality of the early childhood environment, a reduction in taxation may not only raise labor supply but also foster human capital accumulation via the increase in parental time devoted to children.

Other papers study the role of taxation on the allocation of time - see for instance Ragan (2013) and Rogerson (2007). In these papers agents can devote time to market work, leisure and home production. The latter is interpreted as child care, which however is not included in the process of human capital accumulation. In these set-ups the relationship between labor taxation and time devoted to home production/child care is found to be positive. In our paper we show that including child care in the process of skill formation does not change the positive sign of the relationship between taxation and time allocation only if parents are motivated by warm glow altruism. ${ }^{3}$ If they are on the contrary fully altruistic, the sign of the relationship between taxation and the allocation of time to children may become negative.

The paper is organized as follows: in Section 2 we describe the model's building blocks and in Section 3 we discuss the impact of taxation on time allocation comparing a model in which altruism is warm glow with a model in which there is full altruism. Section 4 concludes.

\footnotetext{
${ }^{3}$ Although it does not modify the sign of the relationship between taxation and time allocated to children, the inclusion of child care in the human capital accumulation process in a model with warm-glow altruism influences the relationship between taxation and growth (Casarico and Sommacal (2012)), and the design of optimal fiscal policies (Casarico et al. (forthcoming)).
} 


\section{Basic Set-up}

We develop an OLG model with intragenerational homogeneity and endogenous growth driven by human capital accumulation. Agents have perfect foresight about future variables and are altruistic. They live for three periods -childhood, parenthood and retirement- and have one child in the second period of life. The population is constant, and the size of each generation is equal to $N$.

In the first period, the agent receives child care. In the second period she has one child and decides how much to consume and save and how much time to devote to labor, leisure and the child. The child requires a given care time: the time not supplied by the parent is covered by non-parental time (e.g. day care services) that the parent buys on the market. In the third period, the agent retires and consumes her income.

\section{Production}

In each period, output $Y_{t}$ of a physical good evolves from using capital and labor measured in efficiency units:

$$
Y_{t}=K_{t}^{\delta} L_{t}^{y 1-\delta}
$$

where $K_{t}$ is the capital stock; $L_{t}^{y}=N l_{t}^{y} h_{t}$ is the aggregate labor supply in efficiency units in sector $y$ producing the physical good, with $l_{t}^{y}$ indicating the individual labor supply to this sector and $h_{t}$ the individual human capital. The share of capital income in output is $0<\delta<1$. The physical good can be used for consumption and for investment in physical capital; we choose it as the numeraire.

Non-parental care is derived from using a constant return to scale technology, which employs only labor as input. Because teachers can oversee more than one child at the same time, we follow Lundholm and Ohlsson (1998) and assume that one hour of work in the day care sector produces $\chi>1$ hours of non-parental care.

We assume perfect labor mobility, which guarantees that the wages equalize across the sector producing the physical good and the sector producing nonparental care; thus, there is only one wage per efficiency unit $w_{t}$. Moreover, the zero profit condition implied by perfect competition indicates that the price per hour of non-parental care is $w_{t} h_{t} / \chi$.

\section{Preferences}

The following utility function describes preferences of an agent born in period $t-1$ :

$$
U_{t}=\log c_{t}^{m}+\beta \frac{\left(z_{t}\right)^{\kappa}}{\kappa}+\theta \log c_{t+1}^{o}+\gamma^{w g} \log h_{t+1}+\gamma^{f a} U_{t+1}
$$

where $c_{t}^{m}$ and $c_{t+1}^{o}$ denote consumption during parenthood/middle age and retirement/old age, respectively (no consumption takes place during childhood); $z_{t}$ stands for leisure time and $\kappa \leq 1 ; h_{t+1}$ is the human capital of the child born at time $t$ and $U_{t+1}$ indicates her utility; $\beta$ and $\theta$ are non-negative parameters determining the weight of leisure and consumption during old age, respectively; 
$\gamma^{w g}$ is the weight of the human capital of the child and $\gamma^{f a}$ is the weight of her utility. We consider two alternative environments: the utility function (2) incorporates warm-glow altruism when $\gamma^{w g}>0$ and $\gamma^{f a}=0$, whereas it incorporates full altruism when $\gamma^{w g}=0$ and $\gamma^{f a}>0$.

Human capital production function

We assume that human capital $h_{t+1}$ linearly depends on the quality of the early childhood environment $x_{t}$ :

$$
h_{t+1}=q x_{t}
$$

where $q>0$. This is the simplest way to formalize the idea that the early childhood environment matters for human capital accumulation. ${ }^{4}$

Child care and the quality of the early childhood environment

A child requires an exogenous constant care time $a$, which can be covered either by parental time $n_{t}$ or by non-parental time $d_{t}$. That is:

$$
d_{t}+n_{t}=a \text {. }
$$

Child care (both parental time and non-parental time) produces the quality of the early childhood environment $x_{t}$ according to the following technology:

$$
x_{t}=\left[\sigma\left(d_{t} h_{t}\right)^{\nu}+(1-\sigma)\left(n_{t} h_{t}\right)^{\nu}\right]^{\frac{1}{\nu}} .
$$

The quality of the early childhood environment is a function of parental and non-parental time in efficiency unit. ${ }^{5}$ The parameter $0<\sigma<1$ determines the weight of non-parental time in the production of the quality of the early childhood environment. The parameter $\nu$ governs the elasticity of substitution between $d_{t} h_{t}$ and $n_{t} h_{t}, \zeta_{\nu}=1 /(1-\nu)$, and determines how easy it is to substitute parental with non-parental time. We assume $\nu<1$ and focus on the case of imperfect substitutability between parental and non-parental time. The production function (5) captures the idea that though parents and non-parental care givers have the same level of human capital, the value of being alone with a parent differs from the value of being in a group of peers under teachers' supervision. Therefore, the productivity of parental and non-parental time also differ. For example, the productivity of non-parental time is influenced by the educational content of day care services, which depends not only on the level of human capital of non-parental care givers but also on how a day care center is organized and on its educational policies.

\section{Government budget constraint}

\footnotetext{
${ }^{4}$ Casarico and Sommacal (2012) focus on the growth impact of taxation in a model in which the human capital production function features both early childhood environments and formal schooling as inputs. Here, given that the focus is on taxation and time allocation under different assumptions on altruism, for the sake of analytical tractability, we adopt a simpler specification of the human capital technology.

${ }^{5}$ This production function ignores the parents' monetary investment, which is shown to be less important than time inputs for children cognitive development (see Del Boca et al. forthcoming).
} 
The government budget constraint at $t$ is the following:

$$
\tau N w_{t} h_{t} l_{t}=N T_{t}
$$

where $\tau$ is the tax rate on labor income, $l_{t}=l_{t}^{d}+l_{t}^{y}$ is the total number of hours each person works both as an employee in the day care sector $\left(l_{t}^{d}\right)$ and as an employee in the final good sector $\left(l_{t}^{y}\right)$, and $T_{t}$ is the lump-sum transfer paid back to agents. We take the tax rate $\tau$ as the exogenous policy variable, and we endogenously determine the lump-sum transfer $T_{t}$ to fulfil the budget constraint.

Following some of the existing literature (e.g. King and Rebelo (1990), Stokey and Rebelo (1995), Ihori (2001)), we assume that tax proceeds are returned to the same individual as lump-sum transfers; this assumption allows to isolate the substitution effect of the tax, because the income effect is canceled out; it also allows to separate the effects of taxation from those of government expenditure.

Individual budget constraints

The time and budget constraints are as follows:

$$
\begin{gathered}
l_{t}+z_{t}+n_{t}=1 \\
c_{t}^{m}=w_{t} h_{t} l_{t}(1-\tau)+T_{t}-s_{t}-\frac{w_{t} h_{t}}{\chi} d_{t} \\
c_{t+1}^{o}=\left(1+r_{t+1}\right) s_{t}
\end{gathered}
$$

where $s_{t}$ denotes savings. Equation (7) indicates that during parenthood, agents have one unit of time to devote to labor supply, leisure and parental time with the child. Equation (8) is the budget constraint during parenthood: net earnings plus the lump-sum transfer received can be allocated to consumption, savings, and the purchase of non-parental time. Equation (9) is the budget constraint during retirement: the income of the second period, which is given by savings plus the interests earned on them, goes to consumption.

\subsection{First-order conditions}

Firm's optimization problem

In the final good sector, we assume full depreciation of capital. Profit maximizing behavior of the competitive firms implies the following conditions:

$$
\begin{aligned}
& 1+r_{t+1}=\delta\left(\frac{K_{t+1}}{L_{t+1}^{y}}\right)^{\delta-1} \\
& w_{t+1}=(1-\delta)\left(\frac{K_{t+1}}{L_{t+1}^{y}}\right)^{\delta}
\end{aligned}
$$

which are standard. Equation (10) states that one plus the interest rate $r_{t+1}$ is equal to the marginal productivity of capital. Equation (11) requires that the 
wage per efficiency unit $w_{t+1}$ is equal to the marginal productivity of aggregate labor in efficiency units.

Consumers' optimization problem

Agents choose parental time $n_{t}$, labor supply $l_{t}$ and savings $s_{t}$ to maximize the utility function (2), subject to the time constraints (4) and (7), the budget constraints (8) and (9), the production function of the quality of the early childhood environment (5), and the technology of skill formation (3).

The first-order conditions for an interior solution on the choices of $s_{t}, l_{t}$, and $n_{t}$ can be written as follows:

$$
\begin{gathered}
s_{t}: \frac{1}{c_{t}^{m}}=\left(1+r_{t+1}\right) \theta \frac{1}{c_{t+1}^{o}} \\
l_{t}: \beta\left(z_{t}\right)^{\kappa-1}=\frac{1}{c_{t}^{m}} w_{t} h_{t}(1-\tau) \\
n_{t}: \frac{1}{c_{t}^{m}} w_{t} h_{t}\left[(1-\tau)-\frac{1}{\chi}\right]=\frac{d x_{t}}{d n_{t}} \frac{1}{x_{t}}\left(\gamma^{w g}+\gamma^{f a} q x_{t} \frac{1}{c_{t+1}^{m}} w_{t+1} l_{t+1}(1-\tau)\right)
\end{gathered}
$$

where $\frac{d x_{t}}{d n_{t}} \frac{1}{x_{t}}=\frac{\left[-\sigma\left(a-n_{t}\right)^{\nu-1}+(1-\sigma) n_{t}^{\nu-1}\right] h_{t}^{\nu}}{x_{t}^{\nu}}$.

The first-order conditions for savings and labor supply are standard. Equation (12) requires that the marginal rate of substitution between consumption during parenthood and retirement is equal to one plus the interest rate. Equation (13) requires that the marginal rate of substitution between consumption during parenthood and leisure is equal to the net wage.

Equation (14) reflects the choice of parental time. Parental time affects utility both through consumption and the quality of the early childhood environment. The impact of a change in parental time $n_{t}$ on the utility from consumption appears on the left-hand side of equation (14), where $1 / c_{t+1}^{m}$ is the marginal utility of consumption and $w_{t} h_{t}[(1-\tau)-1 / \chi]$ is the change in consumption. The change in consumption delivered by one additional unit of parental time is given by the net forgone wages $w_{t} h_{t}(1-\tau)$, (i.e. the price of parental time), less the price of non-parental care $w_{t} h_{t} / \chi$. The right-hand side of equation (14) measures the effect of a change in parental time $n_{t}$ on utility through human capital. In the case of warm glow the right hand side reduces to $\frac{d x_{t}}{d n_{t}} \frac{1}{x_{t}} \gamma^{w g}$. In the case of full altruism the right hand side is equal to $\frac{d x_{t}}{d n_{t}} \gamma^{f a} q \frac{1}{c_{t+1}^{m}} w_{t+1} l_{t+1}(1-\tau)$.

We point out that, at an interior solution, if $w_{t} h_{t}[(1-\tau)-1 / \chi]>(<) 0$, then $\frac{d x_{t}}{d n_{t}} \frac{1}{x_{t}}>(<) 0$, which means that a marginal increase in parental time devoted to children improves (worsens) the quality of early childhood environments. As long as the cost of child care in terms of foregone earnings is higher than the cost of child care bought on the market $\left(w_{t} h_{t}[(1-\tau)-1 / \chi]>0\right)$, a parent is willing to spend time with the child only if this is beneficial for the human capital of the child herself $\left(\frac{d x_{t}}{d n_{t}} \frac{1}{x_{t}}>0\right)$. 


\subsection{Equilibrium}

An intertemporal equilibrium is defined as a vector of quantities $\left\{l_{t}^{y}, l_{t}^{d}, z_{t}, n_{t}, d_{t}\right.$, $\left.c_{t}^{m}, s_{t}, c_{t}^{o}, h_{t}, x_{t}, K_{t}, T_{t}\right\}$ and of prices $\left\{w_{t}, r_{t}\right\}$ such that the following equations are satisfied: the first order conditions for consumers (12)-(14) and for firms (10) and (11); the time constraints (4) and (7); the budget constraints (8) and (9) for consumers; the budget constraint for the government (6) and the capital market equilibrium condition

$$
K_{t+1}=N s_{t} .
$$

We focus on a balanced growth path along which $\left\{l_{t}^{y}, l_{t}^{d}, z_{t}, n_{t}, d_{t}\right\}$ are constant and $\left\{c_{t}^{m}, s_{t}, c_{t}^{o}, h_{t}, x_{t}, K_{t}, T_{t}\right\}$ increase at a constant common rate $g_{t+1}=g=$ $h_{t+1} / h_{t}-1$, where

$$
g=\left[\sigma d_{t}^{\nu}+(1-\sigma) n_{t}^{\nu}\right]^{\frac{1}{\nu}}-1
$$

\section{The effects of taxation on time allocation}

In this section we analyze how in equilibrium changes to taxation affect time devoted to labor and child care, distinguishing between a set-up with warm glow and one in which parents are fully altruistic towards their children. We can state the following propositions.

Proposition 1 When $\gamma^{f a}=0$ and $\gamma^{w g}>0$ (warm-glow altruism), provided that $1-\tau-\frac{1}{\chi}>0$, we have $\frac{\partial l}{\partial \tau}<0$ and $\frac{\partial n}{\partial \tau}>0$.

Proof. See Appendix A.

A reduction in taxation increases the net wage, thereby pushing the labor supply up. As the increase in the net wage raises the opportunity cost of parental time provided to children, parents supply less of it: as a result, a higher labor supply is combined with a lower parental time with children.

Proposition 2 When $\gamma^{f a}>0$ and $\gamma^{w g}=0$ (full altruism), provided that 1 $\tau-\frac{1}{\chi}>0$, we have $\frac{\partial l}{\partial \tau}<0$. Moreover, $\frac{\partial n}{\partial \tau}>0$ if and only if

$$
\epsilon \equiv \frac{\partial l}{\partial w(1-\tau)} \frac{w(1-\tau)}{l}<\frac{1}{\chi(1-\tau-1 / \chi)} \equiv \bar{\epsilon}
$$

where $\epsilon$ is the uncompensated elasticity of labor supply with respect to the net wage and $\bar{\epsilon}$ is the threshold level of such elasticity below which the relationship between parental time and the tax rate is positive.

Proof. See Appendix A.

As in the case of warm glow, a reduction in the tax rate increases the labor supply. Furthermore it raises the opportunity cost of parental time, i.e. the left hand side of equation (14). Besides this change, under full altruism there is an 
additional effect to take into account, which depends on the presence of $\tau$ and $l$ on the right hand side of equation (14): the return to parental investment in children's human capital, which is positive when $(1-\tau-1 / \chi)>0$, is higher when taxation is lower because children will work more and will receive higher net wages; these higher returns may offset the increase in the opportunity cost of parental time, and thus the impact of taxation on time devoted to children has an ambiguous sign. The strength of the reaction of the children's labor supply to changes in taxation is critical to assess the overall impact of taxation on parental time. When the uncompensated elasticity of labor supply is high enough, a higher labor supply brought about by a decrease in taxation is combined with higher parental time with children, i.e. $\frac{\partial n}{\partial \tau}<0$. Changes in labor supply are absorbed by changes in leisure rather than by changes in parental time with children. Note that the value of the threshold $\bar{\epsilon}$ for the elasticity of labor supply depends negatively on the parameter $\chi$ and positively on the policy variable $\tau$.

We close this section by offering a numerical example to illustrate the effect of labor taxation on parental time allocation under warm-glow and under full altruism. The starting point is the identification of the threshold value $\bar{\epsilon} \equiv$ $\frac{1}{\chi(1-\tau-1 / \chi)}$ of the uncompensated elasticity of labor supply. With regard to the choice of $\tau$, we use the average of the implicit tax rates ${ }^{6}$ on labor income for a group of European countries ${ }^{7}$ and set the policy parameter $\tau$ to $39 \%$. We choose the productivity parameter of the day care sector $\chi$ equal to 5 . This implies a ratio of the price of one hour of non-parental time $w h_{t+1} / \chi$ to the wage per hour of work $w h_{t+1}$ equal to $20 \%$. Note that these values of the tax rate $\tau$ and of the productivity parameter of the day care sector $\chi$ are such that $1-\tau-\frac{1}{\chi}>0$, which is required for Proposition 1 and 2 to hold. The value of the threshold level of the uncompensated wage elasticity of labor supply we obtain is $\bar{\epsilon}=0.488$ : above this value, a reduction in taxation increases parental time with children under full altruism. ${ }^{8}$ We then choose the parameter $\kappa$ in the utility function (2) to obtain different values for uncompensated wage elasticity of labor supply. ${ }^{9}$ For each of these values, we compute the elasticity of parental time devoted to children with respect to changes in the net wage induced by a variation of the tax rate on labor income. Table 1 shows the results under the assumptions of warm-glow altruism and full altruism and it is an illustration of Propositions 1 and 2.

\footnotetext{
${ }^{6}$ The implicit tax rate is an average effective tax burden indicator that also includes social security contributions. We choose such a comprehensive indicator because the distortionary effects of taxation on time allocation depend on the overall tax burden. The choice of an indicator capturing the average tax burden is consistent with a homogeneous agent model and with the proportional tax schedule we assume herein.

${ }^{7}$ The countries we consider are: Belgium, Finland, France, Germany, Italy, Norway, Spain, Sweden and the United Kingdom.

${ }^{8}$ The selection of a "realistic" value for the uncompensated wage elasticity of labor supply is not straightforward in an aggregate model with a representative agent. Microeconometric estimates provide low values for this elasticity. However, prior research has also stressed that macro elasticities and micro elasticities need not be the same and the former can be much higher than the latter. For a survey on the reconciliation of micro and macro labor supply elasticities see Keane and Rogerson (2012).

${ }^{9}$ For the details of the parameterization and of the calibration, see Appendix B.
} 
Table 1: Wage elasticities

\begin{tabular}{lccccc}
\hline Wage elasticity: labor & 0.338 & 0.388 & 0.488 & 0.588 & 0.638 \\
\hline Wage elasticity: parental time (Warm-glow altruism) & -1.160 & -1.101 & -0.983 & -0.865 & -0.806 \\
Wage elasticity: parental time (Full altruism) & -0.142 & -0.095 & 0.000 & 0.095 & 0.142 \\
\hline
\end{tabular}

Under warm-glow altruism, parental time devoted to children always drops following a rise in the net wage, irrespective of the value of the uncompensated wage elasticity of labor supply. The value of the latter is, on the contrary, important to determine the sign of the wage elasticity of parental time in the presence of full altruism.

As concluding remark we point out that in the paper we focus only on intergenerational time transfers rather than on monetary transfers, that is bequests. We also performed a numerical simulation which includes bequests and we found that results are unaffected.

\section{Conclusions}

In this paper we investigate how changes in taxation influence parental time devoted to children in a model in which child care affects the human capital accumulation process. We show that the relationship between taxation and parental time critically depends on the assumption on parental altruism. We reckon that investigating both motives is important since, to the best of our knowledge, no direct empirical test exists on the type of altruism involved in parental decision to devote time to children. If parents care about their children out of warm glow, lowering the tax rate, reduces parental time devoted to children. If parents care about the utility of their children because they are fully altruistic, we show that a lower taxation may go together with higher parental time devoted to children. This happens when the uncompensated elasticity of labor supply is above a certain threshold. The value of the latter depends on a policy variable, i.e. the tax rate, which may differ across countries, and on the productivity of the day-care sector, which also can be country-specific. The analysis of this paper helps identifying conditions subject to which some countries may experience an increase in the labor supply and in parental time with children following a reduction in labor taxation, whereas some others may face a trade-off.

\section{References}

Aguiar, M., Hurst, E., 2007. Life cycle prices and production. American Economic Review 97(5), 1533-1559.

Baker, M., Gruber, J., Milligan, K., 2008. Universal childcare, maternal labor supply and family well-being. Journal of Political Economy 116, 709-745. 
Berger, T., Heylen, F., 2011. Differences in hours worked in the oecd: Institutions or fiscal policies? Journal of Money, Credit and Banking 43, 1333-1369.

Bernal, R., 2008. The effect of maternal employment and child care on children's cognitive development. International Economic Review 49, 1173-1209.

Bernal, R., Keane, M., 2010. Quasi-structural estimation of a model of childcare choices and child cognitive ability production. Journal of Econometrics 156, 164-189.

Bernal, R., Keane, M., 2011. Child care choices and children's cognitive achievement: the case of single mothers. Journal of Labor Economics 29, 459-512.

Blomquist, S., Christiansen, V., Micheletto, L., 2010. Public provision of private goods and nondistortionary marginal tax rates. American Economic Journal: Economic Policy 2, 1-27.

Cardia, E., Ng, S., 2003. Intergenerational time transfers and childcare. Review of Economic Dynamics 6, 431-454.

Casarico, A., Micheletto, L., Sommacal, A., forthcoming. Intergenerational transmission of skills during childhood and optimal fiscal policies. Journal of Population Economics.

Casarico, A., Sommacal, A., 2012. Labor income taxation, human capital, and growth: The role of childcare. Scandinavian Journal of Economics 114, 11821207.

Del Boca, D., Flinn, C., Wiswall, M., forthcoming. Transfers to households with children and child development. Review of Economic Studies.

Domeij, D., Klein, P., 2013. Should day care be subsidized? Review of Economic Studies 80, 568-595.

Havnes, T., Mogstad, M., 2010. Is universal child care leveling the playing field? Evidence from non-linear difference-in-differences. Discussion Paper 4978, Institute for the Study of Labor (IZA).

Ihori, T., 2001. Wealth taxation and economic growth. Journal of Public Economics $79,129-148$.

Juster, F., 1985. A note on recent changes in time use. In: Juster, F., Stafford, F. (Eds.), Time, Goods, and Well-Being. Institute for Social Research, University of Michigan.

Keane, M. P., Rogerson, R., 2012. Reconciling micro and macro labor supply elasticities: A structural perspective. Economics Papers 2012-W12, Economics Group, Nuffield College, University of Oxford.

King, R., Rebelo, S., 1990. Public policy and economic growth: developing neoclassical implications. Journal of Political Economy 98, 519-550. 
Lundholm, M., Ohlsson, H., 1998. Wages, taxes and publicly provided day care. Journal of Population Economics 11, 185-204.

Ohanian, L., Raffo, A., Rogerson, R., 2008. Long-term changes in labor supply and taxes: Evidence from Oecd countries, 1956-2004. Journal of Monetary Economics 55, 1353-1362.

Prescott, E., 2004. Why do Americans work so much more than Europeans? Federal Reserve Bank of Minneapolis Quarterly Review 28(1), 2-13.

Ragan, K., 2013. Taxes, transfers and time use: fiscal policy in a household production model. American Economic Journal: Macroeconomics 20135.

Rogerson, R., 2007. Taxation and market work: is Scandinavia an outlier? Economic Theory 32 (1), 59-85.

Stokey, N., Rebelo, S., 1995. Growth effects of flat-rate taxes. The Journal of Political Economy 103, 519-550.

\section{Appendix A: proof of Propositions 1 and 2}

We stationarize equations (12)-(14) and focus on a balanced growth path. We denote a stationarized variable with $\mathrm{a}^{\sim}$. Using the stationarized versions of (12), we write $\widetilde{c}^{m}$ as a function of labor supply $l$ and of parental time $n$ and we substitute it into the stationarized version of equation (13) and (14). The choice of $l$ and $n$ are implicitly determined by

$$
\begin{gathered}
\varphi_{1}(l, n, \tau) \equiv \frac{1}{\widetilde{c}^{m}(l, n)} w(1-\tau)-\beta(z)^{\kappa-1}=0 \\
\varphi_{2}(l, n, \tau) \equiv \frac{1}{\widetilde{c}^{m}(l, n)} w\left[1-\tau-\frac{1}{\chi}\right]-\frac{d \widetilde{x}}{d n} \frac{1}{\widetilde{x}}\left(\gamma^{w g}+\gamma^{f a} \frac{1}{\widetilde{c}^{m}(l, n)} w l(1-\tau)\right)=0
\end{gathered}
$$

We apply the implicit function theorem to the system of equations (17)-(18) and we obtain:

$$
\frac{\partial l}{\partial \tau}=-\frac{\left|\begin{array}{ll}
\frac{\partial \varphi_{1}}{\partial \tau} & \frac{\partial \varphi_{1}}{\partial n} \\
\frac{\partial \varphi_{2}}{\partial \tau} & \frac{\partial \varphi_{2}}{\partial n}
\end{array}\right|}{\left|\begin{array}{ll}
\frac{\partial \varphi_{1}}{\partial l} & \frac{\partial \varphi_{1}}{\partial n} \\
\frac{\partial \varphi_{2}}{\partial l} & \frac{\partial \varphi_{2}}{\partial n}
\end{array}\right|}
$$

and

$$
\frac{\partial n}{\partial \tau}=-\frac{\left|\begin{array}{ll}
\frac{\partial \varphi_{1}}{\partial l} & \frac{\partial \varphi_{1}}{\partial \tau} \\
\frac{\partial \varphi_{2}}{\partial l} & \frac{\partial \varphi_{2}}{\partial \tau}
\end{array}\right|}{\left|\begin{array}{ll}
\frac{\partial \varphi_{1}}{\partial l} & \frac{\partial \varphi_{1}}{\partial n} \\
\frac{\partial \varphi_{2}}{\partial l} & \frac{\partial \varphi_{2}}{\partial n}
\end{array}\right|} .
$$


In the case of warm glow (Proposition 1), we have:

$$
\begin{gathered}
\frac{\partial \varphi_{1}}{\partial \tau}=-\frac{w}{\widetilde{c}^{m}} \\
\frac{\partial \varphi_{1}}{\partial n}=-\frac{\frac{\partial \widetilde{c}^{m}}{\partial n}}{\left(\widetilde{c}^{m}\right)^{2}} w(1-\tau)-\beta(1-\kappa) z^{\kappa-2} \\
\frac{\partial \varphi_{1}}{\partial l}=-\frac{\frac{\partial \widetilde{c}^{m}}{\partial l}}{\left(\widetilde{c}^{m}\right)^{2}} w(1-\tau)-\beta(1-\kappa) z^{\kappa-2} \\
\frac{\partial \varphi_{2}}{\partial \tau}=-\frac{w}{\widetilde{c}^{m}} \\
\frac{\partial \varphi_{2}}{\partial n}=-\frac{\frac{\partial \widetilde{c}^{m}}{\partial n}}{\left(\widetilde{c}^{m}\right)^{2}} w\left(1-\tau-\frac{1}{\chi}\right)-\gamma^{w g} \frac{d}{d n}\left(\frac{d \widetilde{x}}{d n} \frac{1}{\widetilde{x}}\right) \\
\frac{\partial \varphi_{2}}{\partial l}=-\frac{\frac{\partial \widetilde{c}^{m}}{\partial l}}{\left(\widetilde{c}^{m}\right)^{2}} w\left(1-\tau-\frac{1}{\chi}\right)
\end{gathered}
$$

After a few manipulations, we can write $\frac{\partial l}{\partial \tau}$ as follows:

$$
\frac{\partial l}{\partial \tau}=-\frac{-\frac{w^{2}}{\left(\widetilde{c}^{m}\right)^{3}} \frac{1}{\chi} \frac{\partial \widetilde{c}^{m}}{\partial n}+\frac{w}{\widetilde{c}^{m}} \gamma^{w g} \frac{d}{d n}\left(\frac{d \widetilde{x}}{d n} \frac{1}{\widetilde{x}}\right)-\beta \frac{w}{\widetilde{c}^{m}}(1-\kappa) z^{\kappa-2}}{\beta(1-\kappa) z^{\kappa-2}\left[\gamma^{w g} \frac{d}{d n}\left(\frac{d \widetilde{x}}{d n} \frac{1}{\widetilde{x}}\right)+\frac{w}{\left(\widetilde{c}^{m}\right)^{2}}\left(1-\tau-\frac{1}{\chi}\right)\left(\frac{\partial \widetilde{c}^{m}}{\partial n}-\frac{\partial \widetilde{c}^{m}}{\partial l}\right)\right]+\frac{\partial \widetilde{C}^{m}}{\left(\widetilde{c}^{m}\right)^{2}} w(1-\tau) \gamma^{w g} \frac{d}{d n}\left(\frac{d \widetilde{x}}{d n} \frac{1}{\widetilde{x}}\right)}
$$

It is possible to show that $\frac{d}{d n}\left(\frac{d \widetilde{x}}{d n} \frac{1}{\widetilde{x}}\right)<0$ and that $\frac{\partial \widetilde{c}^{m}}{\partial l}>\frac{\partial \widetilde{\widetilde{c}}^{m}}{\partial n}>0$.

As to the first inequality, recalling that $\nu<1$, we can find:

$$
\frac{d}{d n}\left(\frac{d \widetilde{x}}{d n} \frac{1}{\widetilde{x}}\right)=\frac{\left[\sigma(\nu-1)(a-n)^{\nu-2}+(1-\sigma)(\nu-1) n^{\nu-2}\right] \widetilde{x}-\nu\left[-\sigma(a-n)^{\nu-1}+(1-\sigma) n^{\nu-1}\right]^{2}}{\widetilde{x}^{2 \nu}}<0
$$

As to the second inequality, using equations (6), (8) and (12), and stationarizing the resulting equation, we find:

$$
\widetilde{c}^{m}=w \frac{1}{1+\theta}\left(l-\frac{a-n}{\chi}\right)
$$

Accordingly:

$$
\begin{gathered}
\frac{\partial \widetilde{c}^{m}}{\partial l}=\frac{w}{1+\theta} \\
\frac{\partial \widetilde{c}^{m}}{\partial n}=\frac{1}{\chi} \frac{w}{1+\theta}
\end{gathered}
$$

Taking into account equations (28), (30) and (31) it follows that both the numerator and the denominator of equation (27) are negative, thus $\frac{\partial l}{\partial \tau}<0$.

As to $\frac{\partial n}{\partial \tau}$, after a few calculations we can write it as

$$
\frac{\partial n}{\partial \tau}=-\frac{\frac{w^{2}}{\left(\widetilde{c}^{m}\right)^{3}} \frac{1}{\chi} \frac{\partial \widetilde{c}^{m}}{\partial l}+\beta \frac{w}{\widetilde{c}^{m}}(1-\kappa) z^{\kappa-2}}{\beta(1-\kappa) z^{\kappa-2}\left[\gamma^{w g} \frac{d}{d n}\left(\frac{d \widetilde{x}}{d n} \frac{1}{\widetilde{x}}\right)+\frac{w}{\left(\widetilde{c}^{m}\right)^{2}}\left(1-\tau-\frac{1}{\chi}\right)\left(\frac{\partial \widetilde{c}^{m}}{\partial n}-\frac{\partial \widetilde{c}^{m}}{\partial l}\right)\right]+\frac{\partial \widetilde{\partial}^{m}}{\left(\widetilde{\boldsymbol{c}}^{m}\right)^{2}} w(1-\tau) \gamma^{w g} \frac{d}{d n}\left(\frac{d \widetilde{x}}{d n} \frac{1}{\widetilde{x}}\right)}
$$


The denominator corresponds to the one in equation (27) and it is negative, whereas the numerator is positive; thus, $\frac{\partial n}{\partial \tau}>0$.

We now focus on the case of full altruism (Proposition 2). Equations (21), (22) and (23) still hold, whereas equations (24), (25) and (26) read as

$$
\begin{gathered}
\frac{\partial \varphi_{2}}{\partial \tau}=-\frac{1}{\chi l(1-\tau)^{2}} \\
\frac{\partial \varphi_{2}}{\partial n}=-\gamma^{f a} \frac{d}{d n}\left(\frac{d \widetilde{x}}{d n} \frac{1}{\widetilde{x}}\right) \\
\frac{\partial \varphi_{2}}{\partial l}=-\frac{1-\tau-\frac{1}{\chi}}{l^{2}(1-\tau)}
\end{gathered}
$$

Starting from $\frac{\partial l}{\partial \tau}$, it is straightforward to see that both the numerator and the denominator of (19) are negative and thus $\frac{\partial l}{\partial \tau}<0$. The sign of $\frac{\partial n}{\partial \tau}$ is instead ambiguous. To identify a condition such that $\frac{\partial n}{\partial \tau}$ is positive or negative, we first note that $\frac{\partial n}{\partial \tau}$ can be written as follows: ${ }^{10}$

$$
\frac{\partial n}{\partial \tau}=-\frac{\frac{\partial \varphi_{2}}{\partial \tau}+\frac{\partial \varphi_{2}}{\partial l} \frac{\partial l}{\partial \tau}}{\frac{\partial \varphi_{2}}{\partial n}}
$$

The denominator of (35) is positive. As to the numerator, we substitute from (32) and from (34); rearranging terms we obtain $\frac{\partial n}{\partial \tau}<0$ if and only if:

$$
\epsilon \equiv \frac{\partial l}{\partial w(1-\tau)} \frac{w(1-\tau)}{l}>\frac{1}{\chi(1-\tau-1 / \chi)} \equiv \bar{\epsilon}
$$

where $\epsilon$ is the uncompensated elasticity of labor supply with respect to the net wage and $\bar{\epsilon}$ is the threshold level of the elasticity of labor supply above (below) which the relationship between parental time and the tax rate is negative (positive).

\section{Appendix B: Calibration}

We interpret each period as having a length of 25 years. We set the time span over which child care is provided to 6 years; thus, $a=6 / 25=0.24$. This means that $24 \%$ of the first period of life is spent receiving child care. Because population is constant, we normalize its size $N$ at 1 .

We choose the parameter $\beta$ in the utility function (2) and the parameter $\sigma$ in the production function of the quality of child care (5) to generate a realistic allocation of time between labor and parental time with the child. Leisure is residually determined using the time constraint (7). In line with previous

\footnotetext{
${ }^{10}$ This can be verified substituting (19) in (35) and rearranging terms: the resulting expression corresponds to $(20)$.
} 
research (e.g. Juster (1985); Cardia and Ng (2003); Ragan (2013)), we assume that non-personal time available for discretionary use amounts to 100 hours per week. Average data from the Harmonized European Time Use Survey (HETUS) ${ }^{11}$ indicate that $32 \%$ of the time endowment is devoted to work and $6 \%$ is devoted to parental care. ${ }^{12}$

As to the parameter $\nu$ which governs the elasticity of substitution between $d_{t} h_{t}$ and $n_{t} h_{t}, \zeta_{\nu}=1 /(1-\nu)$, see equation (5), we know the existing estimates that refer to the elasticity of substitution between inputs in the production of the general category of home-produced goods. For example, in their estimates, Aguiar and Hurst (2007) suggest a value of $\nu=0.6$. We use this value, although we are aware that this estimate pertains to a large set of home-produced goods and not just to the quality of child care. To the best of our knowledge, direct estimates of the elasticity of substitution between non-parental time and parental time in the production of the quality of the early childhood environment are not available.

The intertemporal discount factor $\theta$ is chosen in order to have a ratio of gross savings to GDP equal to 0.23 . We choose $\delta$, which is the share of capital income in national product, equal to 0.33 . We choose the parameter $q$ of the human capital production function to obtain an annual growth rate of GDP per capita $\left((1+g)^{\frac{1}{25}}-1\right)$ equal to $2 \%$ which is the average value for the set of countries we consider.

\footnotetext{
${ }^{11}$ The countries we consider are reported in footnote 7 . Data refer to people in the 25-50 age group, which corresponds in our three-period OLG model to the second period of life. The period we consider is 1999-2004. This is the reference period for all the average data we use in the calibration.

${ }^{12}$ Two issues are important in interpreting these data. First, we define parental time as the sum of the minutes registered as devoted to primary and secondary child care. Second, we define leisure as a residual category; that is, it is the time not spent either working or doing primary and secondary child care: thus, it is not a measure of leisure only because it also includes, for example, housework.
} 